\title{
ANARKISME DAN SENSUALISME TELEVISI INDONESIA
}

\author{
Nur Hamzah \\ Dosen Jurusan PGRA FTIK IAIN Pontianak \\ Email: hamzah_ptk@yahoo.com
}

\begin{abstract}
Nowadays, television could not be separated from sophisticated people. Furthermore, for the most of people, television is an accompanying. Meanwhile, it is used as a source of information and entertainment for others. The modern people evenly depend on television. However, television does not merely afford the enjoyment and educative values, it also possesses the dark sides and negative effects. Based on Cultivation Theory, people who watch television intensely more than 4 hours tend to construct the aired program as a reality. It is similar to Indonesian television businesses, due to the number of advertisements, not all programs could be watched. For instance, Ganteng-ganteng Srigala, 7 Manusia Harimau, Naruto and so forth, contain the negative values, such as anarchism, vandalism, and sensuality. Eventually, if the adults do not undertake the strengthening effort to filter the negative programs, the audiences perbaps will fall to the negative values of television.
\end{abstract}

\section{Keywords: Anarchism, Television}

Periode abad XX adalah babak baru revolusi pertelekomunikasian dunia. Pada periode ini ditandai dengan penemuan spektakuler dengan teknologi tinggi seperti komunikasi satelit, serat optik, internet, radar, telpon mobile dan lain-lain. Kecanggihan pertelekomunikasian bagi sebagian orang menyebutnya dengan globalisasi informasi. Globalisasi informasi meniscayakan dunia menjadi desa kecil yang mampat. Dengan teknologi jarak-ruang semakin diperkecil dan diperpendek. Konsep waktu juga dimampatkan pada wilayah ini. Dulu orang hanya mengerjakan satu pekerjaan dalam satu waktu. Dengan teknologi, orang dapat mengerjakan beberapa hal dalam waktu bersamaan. Memasak sambil menonton televisi, sambil menerima telpon, sambil mengirim email dan lain sebagainya.

Menurut istilah Jhon Keane yang dikutip oleh Yasraf Amir Pilliang (2005,12), saat sekarang sedang terjadi "keberlimpahan komunikasi" atau "tumpah-ruah komunikasi". Segala macam bentuk informasi, yang datang dari mana saja menjadi menu suguhan setiap saat, mulai dari informasi politik, ekonomi, sosial, budaya, kehidupan selebritis, olah raga, pesta dan lainlainnya lagi. Ia dapat diakses oleh siapa saja tanpa pembatas usia, tua, dewasa, remaja bahkan anak-anak sekalipun. Ia juga dapat dinikmati baik dalam bentuk gambar visual, audio, ataupun teks. Semuanya sekarang ini telah diredusir dalam bentuk layar kaca baik televisi maupun komputer dan telah menjadi ruang private karena ia dapat diakses dalam sebuah bilik kamar tidur. Masyarakat sekarang ini telah betul-betul kebanjiran informasi.

Fenomena kelimpah-ruahan informasi ini tentu saja juga menyertakan dampak negatif. Terkadang sajian informasi tanpa sungkan mempertontonkan wilayah yang dulu dianggap tabu dan sakral. Informasi menjadi senjata yang menelusuk ruang dan batas-batas moralitas. Dieter Lenze (dalam Pilliang, 2005) juga mengatakan bahwa televisi dan video juga telah menghilangkan batas sosiologis. Yang tadinya vandalisme, anarkisme, kriminalitas bahkan sexsualitas hanya untuk orang dewasa, karena televisi dapat ditonton anak-anak, maka batas antara dewasa dan anak menjadi tidak ada lagi. Dalam bahasa yang lebih sedikit filosofis, kita yang telah mengakses 
informasi sebenarnya telah terdikte dan terdominasi oleh informasi itu sendiri. Kita menghayati nilai-nilai yang ditawarkan bahkan mengamalkannya. Begitulah konsekuensi dari banjir bah informasi, apa yang diperoleh oleh manusia bukan justru peningkatan kualitas kemanusiaan dan spiritualitas tetapi justru sebuah penggerusan dari elan vital manusiawi dan spiritual.

Kasus Indonesia, kelimpah-ruahan informasi ini ditandai dengan munculnya banyak stasiun televisi swasta baik nasional maupun daerah. Ini adalah buah reformasi dan sebagian besar kita menyambut baik terhadap hal ini. Hal ini lantaran kita atau publik merasa memperoleh tambahan berbagai sajian acara baru yang lebih beragam. Banyaknya pilihan ini diharapkan akan memberikan pencerahan budaya sekaligus pencerdasan memlalui sajian program yang variatif.

Namun tidak dapat dihindari kehadiran televisi swasta yang banyak ini menghadirkan kompetisi ketat antar stasiun televisi. Sebagai konsekuensinya para pemegang bisnis pertelevisian harus memutar otak dan menyusun strategi matang untuk merebut hati pemirsa. Dengan ditonton oleh khalayak ramai, maka rating sebuah acara akan naik dan iklan juga akan semakin banyak serta mahal. Inilah yang dilakukan para pebisnis televisi.

Hanya yang menjadikan kita prihatin adalah bahwa sebagian televisi swasta tidak memiliki idealisme. Mereka lebih memilih program atau tayangan yang non-edukatif. Wal hasil program yang mempertontonkan vulgarisme, lawakan non edukatif, pornografi dan kekerasan adalah bentuk mata acaranya. Jika di lihat, tidak ada stasiun tv yang tidak menayangkan keempat bidang acara tersebut.

Bagi orang dewasa sebenarnya hal tersebut bukan menjadi masalah besar manakala ia memfilter dengan baik. Dapat membedakan mana pelajaran positif, dan mana informasi sampah yang wajib dibuang. Tetapi kemudian bagaimana dengan anak-anak? Secara kognitif dan psikologis anak sebenarnya belum mampu memilah tayangan televisi mana yang edukatif dan pas dengan perkembangannya. Anak juga belum dapat memilih dan menganalisis tayangan yang berdampak negatif dan positif. Wal hasil anak menyerap secara telanjang informasi yang disajikan, apa lagi jika saat anak menonton tanpa didamping orang dewasa.

Jika melihat fakta sekarang, televisi telah menjadi sahabat aktif anak-anak di rumah. Televisi telah menjalankan fungsi ganda yakni sarana penghibur juga menjadi tutor kehidupan pengganti orangtua dan guru. Nilai-nilai dalam sebuah tayangan program diadopsi oleh anak untuk dijadikan perilaku. Dalam sebuah majalah elektornik penulis pernah membaca, seorang anak terinspirasi memotong urat nadinya setelah menonton berita kriminal di salah satu stasiun televisi swasta. Masalah yang ia hadapi saat itu adalah ditagih uang Sumbangan Penyelenggaraan Pendidikan (SPP) di sekolah. Tayangan televisi dapat memberikan inspirasi untuk berbuat sesuatu. Belum lagi kasus-kasus kekerasan yang dilakukan oleh anak baik perorangan atau massal. Hampir dipastikan logika simplistis yang mereka pakai yakni menyelesaikan masalah dengan kekerasan. Di televisi mereka menonton para elit bertengkar bahkan gontok-gontokan, mengapa kita yang masih remaja tidak melakukan hal yang serupa. Logika-logika simplistis seperti ini akan memperparah keadaan.

Teori belajar sosial Albert Bandura menjelaskan bahwa anak belajar menggunakan model. Model yang dimaksud adalah apa yang dilihat, dialami dan di dengar dari orang dewasa, itu lah yang menjadi contoh untuk ditiru. Anak akan melakukan hal serupa sebagaimana yang dilakukan oleh orangtua, guru dan orang dewasa lainnya. Jika setiap saat mereka melihat televisi baik dalam bentuk berita, sinetron, iklan atau lawakan sekalipun, niscaya mereka juga melakukan 
hal serupa. Jika model tersebut positif, anak akan bertingkah positif juga. Sebaliknya jika jejalan modelnya selalu negatif maka anak akan bertingkah negatif juga.

Televisi saat ini tidak dapat dipisahkan dari kehidupan manusia modern. Televisi bagi sebagian orang adalah teman saat diwaktu luang. Sebagian lagi sebagai sumber informasi, dan sebagai sarana hiburan. Hampir rata-rata manusia modern tergantung dengan televisi.

Televisi merupakan sarana utama masyarakat untuk belajar tentang dunia, orangorangnya, nilai-nilainya serta kebiasaannya. Perilaku menonton televisi inilah yang kemudian bagi George Gerbner dkk menginspirasi melakukan penelitian terhadap orang-orang dengan tabiat menonton televisi hingga empat jam lebih dalam sehari. Hasil penelitiannya kemudian menghasilkan sebuah teori yang diberinama teori kultivasi.

Menurut teori kultivasi, televisi menjadi media atau alat utama dimana para penonton televisi itu belajar tentang masyarakat dan kultur dilingkungannya. Dengan kata lain, persepsi apa yang terbangun di benak individu tentang masyarakat dan budaya sangat ditentukan oleh televisi. Ini artinya, melalui kontak individu dengan televisi, individu belajar tentang dunia, orangorangnya, nilai-nilainya serta adat kebiasannya (Ricard West dan Lynn H. Turner: 2007).

Televisi, sebagaimana Gerbner, dianggap sebagai pendominasi "lingkungan simbolik" kita. Sebagaimana McQual dan Windahl catat pula, teori kultivasi menganggap bahwa televisi tidak hanya disebut sebagai jendela atau refleksi kejadian sehari-hari di sekitar kita, tetapi dunia itu sendiri. Gerbner (meminjam istilah Bandura) juga berpendapat bahwa gambaran tentang adegan kekerasan televisi lebih merupakan pesan simbolik tentang hukum dan aturan. Dengan kata lain, perilaku kekerasan yang diperlihatkan di televisi merupakan refleksi kejadian di sekitar kita. Jika adegan kekerasan itu merefleksikan aturan hukum yang tidak bisa mengatasi situasi seperti yang digambarkan dalam adegan televisi, bisa jadi yang sebenarnya terjadi juga begitu. Jadi, kekerasan televisi dianggap sebagai kekerasan yang memang sedang terjadi di dunia ini. Aturan hukum yang bisa digunakan untuk mengatasi perilaku kejahatan yang dipertontonkan di televisi akan dikatakan bahwa seperti itulah hukum kita sekarang ini (Nurudin: 2007).

Memakai kacamata kultivasi, ada perbedaan antara pandangan orangtua dengan remaja tentang suatu permasalahan. Melalui perbedaan kultivasi, orantua ditampilkan secara negatif di televisi. Bahkan para pecandu televisi (terutama kelompok muda) lebih mempunyai pandangan negatif tentang orangtua dari pada mereka yang bukan termasuk kelompok kecanduan. Mengapa ini semua terjadi? Karena sebelumnya, televisi telah memotret atau selalu menampilkan sisi negatif dari orangtua. Misalnya, bagaimana mereka sering terlihat kolot dalam memahami dan menyelesaikan kasus yang berhubungan dengan anak muda. Seolah, para pecandu televisi ini tidak sadar bahwa televisi punya banyak pengaruh terhadap sikap dan perilaku mereka.

Termasuk di sini konflik antara orangtua dan anak. Benak penonton itu akan mengatakan saat ini semua anak memberontak kepada orangtua tentang perbedaan antara keduanya. Mereka yakin bahwa televisi adalah potret sesungguhnya dunia nyata. Padahal seperti yang bisa dilihat dalam kenyataannya, tidak sedikit anak-anak yang masih hormat atau bahkan selalu mengiyakan apa yang dikatakan orang tua mereka.

Pertanyaan kemudian, mengapa televisi sangat berpengaruh kepada penontonnya. Beberapa asumsi pokok dari teori ini dapat dijelaskan sebagai berikut sebagaimana disampaikan Slamet Mulyana (2009):

1. Televisi merupakan media yang unik. Keunikan tersebut ditandai oleh karakteristik televisi yang bersifat: a. Pervasive (menyebar dan hampir dimiliki seluruh keluarga). b. Assesible (dapat 
diakses tanpa memerlukan kemampuan literasi atau keahlian lain). c. Coherent (memprsentasikan pesan dengan dasar yang sama tentang masyarakat melintasi program dan waktu).

2. Semakin banyak seseorang menghabiskan waktu untuk menonton televisi, semakin kuat kecenderungan orang tersebut menyamakan realitas televisi dengan realitas sosial.

3. Penonton ringan (light viewers) cenderung menggunakan jenis media dan sumber informasi yang lebih bervariasi (baik komunikasi bermedia maupun sumber personal), sementara penonton berat (heavy viewers) cenderung mengandalkan televisi sebagai sumber informasi mereka.

4. Terpaan pesan televisi yang terus menerus menyebabkan pesan tersebut diterima khalayak sebagai pandangan konsensus masyarakat.

5. Televisi membentuk mainstreaming dan resonance. Mainstreaming diartikan sebagai kemampuan memantapkan dan menyeragamkan berbagai pandangan di masyarakat tentang dunia di sekitar mereka Dalam proses ini televisi pertama kali akan mengaburkan (bluring), kemudian membaurkan (blending) dan melenturkan (bending) perbedaan realitas yang beragam menjadi pandangan mainstream tersebut. Sedangkan resonance mengimplikasikan pengaruh pesan media dalam persepsi realita dikuatkan ketika apa yang dilihat orang di televisi adalah apa yang mereka lihat dalam kehidupan nyata.

6. Perkembangan teknologi baru memperkuat pengaruh televisi.

Jadi, meskipun televisi bukanlah satu-satunya sarana yang membentuk pandangan dan perilaku individu termasuk anak, televisi merupakan salah satu media yang paling ampuh, terutama bila kontak dengan televisi yang sangat sering dan berlangsung dalam waktu lama.

Jika melihat banyak program televisi yang tayang saat ini, sepertinya kita harus bekerja keras untuk membendung dan memfilter dampak negatif tayangan tersebut. Beberapa tayangan tersebut saat ini menjadi tontonan favorit baik orang dewasa, remaja hingga anak-anak, bahkan oleh salah satu merek dagang terkenal dianugerahi penghargaan sebagai sinetron laga terfavorit. Beberapa diantara contoh program televisi yang menurut penulis mimiliki nilai paradoks ialah sinetron Ganteng-ganteng Srigala SCTV, Sinetron 7 Manusia Harimau RCTI, Kartun Naruto Global TV dan lain-lain.

Sinetron Ganteng-ganteng Srigala (GGS) mengambil setting pertempuran antara serigala, drakula dan manusia. Alur cerita yang disuguhkan adalah drama mempertahankan koloni, dendam, intrik antara serigala dan drakula dengan dibumbui percintaan remaja. Nilai yang ditonjolkan adalah kekerasan, vandalisme, intoleransi, dendam dan termasuk sensualisme baik dari aspek pakaian maupun adegan tokoh.

Sementara sinetron 7 Manusia Harimau mengambil setting dan kultur kampungan Minangkabau dengan alur cerita pertentangan dan perebutan kekuasaan antara manusia (masyarakat kampung) dengan siluman. Kampung Kanayan dijaga oleh para Innyek yaitu manusia siluman yang dapat berubah bentuk menjadi harimau. Para Innyek memiliki ilmu kanuragan tinggi, mewakili siluman berwatak baik penjaga kampung. Sementara watak jahat diwakili oleh Ratu Hangcinda yang selalu ingin merusak dan menguasai kampung. Pertentangan antara dua kekuatan ini selalu diwarnai dengan perkelahian. Dalam sinetron ini nilai negatif tersembunyi (bidden value) yang muncul adalah kekerasan, dendam, kesombongan dan ambisi. 
Untuk acara anak di televisi, hampir rata-rata program tayangan stasiun televisi mengimpor karya luar terutama dari Jepang. Lihat saja beberapa film kartun tersebut: Naruto, Spongebob Squerpants, Shincan, Dora Emon, Matsubilami, termasuk Upin Ipin dan Pada zaman dahulu. Kesemua kartun tersebut memiliki nilai sendiri-sendiri dan yang pasti nilai kultur dalam kartun tersebut tidaklah sama dengan nilai kultur yang bangsa Indonesia miliki.

Kita boleh berbangga kepada stasiun televisi Trans7 yang memiliki acara anak terkenal dan familiar ditelinga dan mata anak Indonesia yaitu Si Bolang, Laptop Si Unyil, Dunia Binatang, dan lain-lain. Si Bolang atau bocah petualang adalah salah satu program petualangan anak-anak di TRANS7. Program ini mencoba mendekatkan kembali anak-anak di seluruh Nusantara dengan alam dan budayanya. Bagaimana si anak berinteraksi dengan alam, budaya, dan bermain dengan beraneka ragam permainan tradisional. Selain itu, sisi-sisi human interest sang tokoh ketika menghadapi suatu masalah juga ditampilkan di film semi dokumenter ini. Si Bolang adalah sebutan dari seorang anak setempat yang memimpin teman-temannya berpetualang di sekitar tempat tinggalnya. Hampir disetiap episodenya, bocah-bocah dan tokoh Si Bolang akan menampilkan petualangan-petualangan seru (www.trans7.co.id).

Sementara tontonan Laptop Si Unyil menayangkan berbagai hal mengenai kehidupan yang dialami oleh anak. Misalkan tentang alat-alat perabot rumah tangga, kendaraan yang sering digunakan, bahan bakar, mainan, rumah dan lain sebagainya. Yang menarik adalah tema-tema tersebut disajikan secara edukatif. Dijelaskan dengan menggunakan cerita dan peran tokoh Unyil dan kawan-kawan tentang bagaimana proses sesuatu terjadi atau dibuat, dari awal hingga menjadi sebuah produk yang siap pakai. Selain penjelasan tentang sebuah produk, film semi dokumenter ini juga melakukan percobaan-percobaan ilmiah sederhana yang disesuaikan dengan tingkat perkembangan anak. Setting yang diambil juga adalah setting asli sesuai tema yang diangkat misalkan di pabrik pembuat mainan, pabrik boneka, pabrik pembuat alat perabot rumah tangga, di kapal laut dan lain-lain.

Tetapi walaupun demikian ketika diteliti iklan yang tayang pada acara tersebut, penulis masih menemukan beberapa iklan yang tidak sesuai dengan materi tontonan. Semisal pada acara Si Bolang, terdapat iklan yang tayang seperti iklan produk makanan coklat. Iklan ini bermaterikan seorang wanita yang sedang menikmati lezatnya salah satu produk coklat. Yang menjadi hal negatif dari iklan ini adalah pakaian dan perilaku sensual saat memakan coklat, karena dengan wanita sang bintang iklan memakan coklat dengan gaya menggoda, mimik wajah dan bibir yang dapat membangkitkan birahi. Iklan berikutnya lagi yaitu, iklan coklat dengan merek berbeda. Iklan ini bermaterikan seorang anak laki-laki yang mencoba menjahili anak perempuan lainnya, lantas dibalas oleh sang gadis kecil dengan memakan coklat dan si anak laki-laki yang menjahili tadi menjadi patung coklat. Kelemahan dari iklan ini adalah sifat nakal dan menjahili teman. Selanjutnya perilaku jahil ini juga di balas dengan perilaku jahil pula. Ke dua perilaku ini jelas melanggar tata moral positif.

Iklan selanjutnya yang bermasalah menurut penulis adalah iklan salah satu produk kecantikan (shampoo). Materi dari iklan ini adalah seorang gadis yang baru bangun dari tidur dengan rambut acak-acakan, setelah menggunakan shampoo tersebut rambut sang bintang iklan tertata rapi dan mengkilau. Aspek negatif dari iklan ini adalah pakaian sang bintang iklan adalah pakaian tidur yang sangat pendek seksi, jadi terlalu menampilkan sensualitas. Sejatinya acara anak seperti Si Bolang dan Laptop Si Unyil diatas memiliki banyak manfaat bagi para penontonnya 
dalam hal ini anak, tetapi karena stasiun televisi harus mencari hidup untuk survive dan eksist dari iklan.

Survive-nya stasiun televisi swasta adalah karena iklan yang tayang, maka secara ekonomis berbagai upaya dilakukan oleh perusahaan agar iklan dapat masuk pada acara yang mereka tayangkan. Acara yang dibuat agar dapat ditonton oleh banyak orang dengan demikian iklan juga dengan sendirinya akan mau tayang. Disinilah kadang idealisme perusahaan menjadi sangat labil karena berhadap-hadapan dengan kepentingan ekonomis. Implikasi dari hal ini, maka perusahaan akan membuat acara yang marketable baik bagi penonton ataupun perusahaan pengiklan. Konsekuensinya sudah bisa ditebak bahwa acara yang dibuat tidak lagi memperhatikan nilai-nilai idealisme. Kalau sudah seperti itu maka televisi tidak lagi menjadi wadah pendidikan nilai malah menjadi agen penyebar nilai kekerasan, vandalisme dan sensualisme atau nilai negatif lainnya.

Permasalahan yang penulis sebutkan diatas bagaikan lingkaran setan dimana begitu sulit harus mengamputasinya untuk menyelesaikan masalahnya. Tetapi bukan tanpa solusi yang dapat dilakukan oleh bangsa ini apa lagi jika dilakukan secara bersama-sama dan sistematis. Beberapa solusi yang dapat penulis tawarkan diantaranya:

1. Pemerintah harus melakukan kontrol lebih "kuat" terhadap iklim kebebasan pers agar nilai neo-liberalisme (kebebasan, sensualitas, anarkbisme dan vandalisme) yang terkadang menjadi penumpang gelap menjadi terfilter oleh nilai luhur bangsa sendiri;

2. Merevisi undang-undang kebebasan pers;

3. Memperkuat posisi KOMINFO dan KPI;

4. Memproteksi arus informasi global. $\left(^{*}\right)$

\section{REFERENSI}

Achmad Sudrajat, Teori Belajar, http://:www.iasi-jerman.

Elizabeth Hurlock, Perkembangan Anak, Jilid 1, Erlangga, Jakarta

Harja Saputra, 2011 dalam http://www.harjasaputra.com..

Lusianti Tamara, 2006, http://lib.unnes.ac.id

Pengantar Komunikasi Massa. Jakarta : PT. Rajagrafindo Persada. 2007

Ricard West dan Lynn H. Turner, Introducing Communication, McGraw-Hill International, 2007.

Slamet Mulyana, Teori Kultivasi, www.wordpress.com/2009Nurudin.

Santrock, Life-Span Development Perkembangan Masa Hidup, (Jilid 1, Erlangga, Jakarta, 1995)

Saifuddin Azwar, Sikap Manusia, Teori dan Pengukuran, (Pustaka Pelajar, Yogyakarta, edisi 2, 1995)

Yasraf Amir Pilliang, Dunia yang Dilipat, (Jalasutra, Jakarta, 2005) 